\title{
Evaluation of a group family-based intervention programme for adolescent obesity: the LITE randomised controlled pilot trial
}

Chu Shan Elaine $\underline{C h e w}^{1}$, MBBS, MMed, Jean Yin $\mathrm{Oh}^{1}$, MB BCh BAO, MRCPCH, Kumudhini Rajasegaran ${ }^{1}$, MB BCh BAO, MRCPCH, Seyed Ehsan Saffari' ${ }^{2}$, PhD, Chee Ming Micheal $\underline{\mathrm{Lim}}^{3}$, BSc, GDHM, Siew Choo Lim${ }^{4}$, BSc, Shiling $\underline{\operatorname{Tan}}^{4}$, BSc,

Siobhan Kelly ${ }^{5}$, DClinPsych, MSc

INTRODUCTION This study aimed to evaluate the LITE (Lifestyle Intervention for TEenagers) group programme, a familybased behavioural lifestyle intervention for overweight and obese adolescents.

METHODS We conducted a two-arm randomised controlled trial that recruited overweight and obese adolescents who attended a tertiary care weight management clinic. Participants were randomised to the LITE programme or usual care. The primary outcome assessed was body mass index (BMI) z-score. Secondary outcomes of anthropometric measurements, metabolic profile, parenting and adolescents' perception of family support were measured at baseline, three months and six months. Feasibility and acceptability of the LITE programme were also evaluated.

RESULTS 61 adolescents were enrolled, with 31 in the LITE programme and 30 in usual care. At three months, participants in the programme had a greater reduction in weight $(-0.18 \pm 2.40 \mathrm{~kg}$ vs. $1.48 \pm 1.97 \mathrm{~kg} ; \mathrm{p}=0.107)$, waist circumference $(-1.0 \pm 3.1 \mathrm{~cm}$ vs. $2.4 \pm 2.7 \mathrm{~cm} ; \mathrm{p}=0.016)$, waist-height ratio $(-0.01 \pm 0.02 \mathrm{vs} .0 .01 \pm 0.02 ; p=0.040)$ and systolic blood pressure $(-3.8 \pm 13.7$ vs. $5.7 \pm 13.1 ; p=0.119)$ compared to the usual care group. There was no significant difference in BMI z-score. At six months, there were significant improvements in adolescents' perception of family support for eating habits in the LITE group compared to the usual care group. The LITE programme had a good attendance rate of $67.7 \%$ and was well received.

CONCLUSION The LITE programme showed feasibility and short-term clinical effectiveness in improving some clinical outcomes and improved adolescents' perception of family support.

Keywords: adolescent, body mass index, family intervention, obesity, parenting

\section{INTRODUCTION}

Child and adolescent obesity rates have soared globally over the past decade, especially in low- and middle-income countries. Although childhood and adolescent obesity appears to plateau in high-income countries, the rates continue to remain high. ${ }^{(1)}$ Overweight or obese adolescents have a moderate to substantial risk of remaining so in adulthood. ${ }^{(2,3)}$ Adult obesity has considerable medical and economic consequences, accounting for a wide range of conditions such as cardiovascular diseases, metabolic syndrome resulting in higher rates of disability, excess mortality, lower productivity and higher medical costs. ${ }^{(4)}$ Interventions at this stage of life are thus critical for the current and future well-being of the adolescents and were found to be a potential window of opportunity for reversal of obesity. ${ }^{(3)}$

There is no current best practice intervention for adolescent obesity. A few promising studies engaged a mixture of a familybased approach and adolescent-only sessions. ${ }^{(5)}$ Our Adolescent Weight Management Clinic at KK Women's and Children's Hospital, Singapore, is a tertiary-level programme that involves regular, scheduled consultations with a pediatrician, dietitians and exercise trainers. The clinic and dietetic sessions are conducted with both parents and adolescents, while exercise sessions are mainly adolescent focused. Adolescents aged 10-16 years are reviewed every 1-6 months depending on the patient's medical condition and motivation. The weight management programme has shown some improvement in overweight status of adolescents with reductions in body mass index (BMI) z-scores of 0.15 (95\% confidence interval $[\mathrm{Cl}]-0.23,-0.06 ; \mathrm{p}=0.001)^{(6)}$ over the programme period. This is clinically relevant, as a reduction of more than 0.15 has been demonstrated to be associated with decreased cardiovascular risk factors, ${ }^{(7-9)}$ although the high default rate of the programme limits the generalisability of the result.

There is no previously known family-based group intervention for adolescent obesity in multiracial Singapore. This is especially relevant for interventions in obesity that have to take racial and ethnic differences into account, ${ }^{(10)}$ prompting our pilot work in Singapore to develop a family-based group intervention programme for adolescent obesity to complement our more adolescent-focused tertiary weight management programme. To the best of our knowledge, this study is the first randomised controlled trial of a family-based group intervention programme for adolescent obesity in this region. The present study aimed to evaluate the clinical outcomes of the LITE (Lifestyle Intervention for TEenagers) programme compared to usual care. We also aimed to evaluate the feasibility and acceptability of the programme prior to the planning of a larger study.

${ }^{1}$ Adolescent Medicine Service, KK Women's and Children's Hospital, ${ }^{2}$ Centre for Quantitative Medicine, Duke-NUS Medical School, ${ }^{3}$ Family Medicine Service, ${ }^{4}$ Department of Nutrition and Dietetics, ${ }^{5}$ Psychology Service, KK Women's and Children's Hospital, Singapore

Correspondence: Dr Chew Chu Shan Elaine, Consultant, Adolescent Medicine Service, KK Women's and Children's Hospital, 100 Bukit Timah Road, Singapore 229899. elaine.chew.c.s@singhealth.com.sg 


\section{METHODS}

Between November 2014 and July 2015, adolescents who were enrolled in our Adolescent Weight Management Programme were invited to participate in the study. Adolescents aged 10-16 years who were enrolled in the programme were eligible. Exclusion criteria included: individuals with obesity as a secondary cause, those who were taking medications (e.g. metformin or insulin) that can affect weight status, and those with severe obesity (defined as BMI $\geq 40 \mathrm{~kg} / \mathrm{m}^{2}$ ). Patients were not included if they had an intellectual disability, a poor level of spoken English (including by their parent or carer), a significant medical illness that precluded physical activity, a significant psychiatric illness or a sibling who was already participating in the study. Written informed consent was taken from eligible adolescents and their parents or caregivers. Randomisation was done using computer-generated random sequences stratified by gender and age group (10-12 years and 13-16 years).

The trial was registered with ClinicalTrials.gov (NCT 03458637) and ethics approval was obtained from the SingHealth Centralised Institution Review Board. Informed consent was obtained from both the parent and adolescent after explanation of the study protocol. Both parental consent and assent were obtained from adolescents aged 10-12 years. Both parental consent and adolescent consent were obtained from adolescents aged $\geq 13$ years

All participants in the study received usual care consisting of a paediatrician review at baseline, three months and six months, lasting about 20-30 minutes. The purpose of the visit was to screen for the medical complications of obesity and assess for morbidity risk. The paediatrician also used brief motivational interviewing techniques to enable behavioural change. All participants had a dietitian review at baseline and six months to assess their dietary intake and provide dietary advice on food choices and eating patterns according to the Health Promotion Board's guidelines for the management of overweight and obesity. ${ }^{(11)}$ All participants had an individual physical activity counselling session ${ }^{(12)}$ as per the National Physical Activity Guidelines at baseline and six months.

The intervention consisted of four 180-minute weekly sessions followed by three 90-minute monthly sessions. All sessions were parent-and-child group sessions. The key aspects of the LITE programme are in keeping with Health Promotion Board guidelines for the management of overweight and obesity and include adopting healthy food choices and eating patterns, increasing physical activity and reducing sedentary behaviour. The different sessions and guidelines are detailed in Table I. The

Table I. Summary of session contents and guidelines.

\begin{tabular}{|c|c|c|}
\hline Session & Participant's programme & Caregiver's programme \\
\hline 1 & $\begin{array}{l}\text { - Eating out } \\
\text { - Ice breaker } \\
\text { - Group rules } \\
\text { - Choosing healthier alternatives } \\
\text { - Setting SMART goals } \\
\text { - Energy balance (types of physical activity } \\
\text { matched with food intake) }\end{array}$ & $\begin{array}{l}\text { - Eating out } \\
\text { - Ice breaker } \\
\text { - Group rules } \\
\text { - Choosing healthier alternatives for the family } \\
\text { - Medical complications of obesity } \\
\text { - Parental role in family lifestyle changes } \\
\text { - Setting family-oriented SMART goals }\end{array}$ \\
\hline 2 & $\begin{array}{l}\text { - Family meal } \\
\text { - Portion sizes } \\
\text { - Regular meals } \\
\text { - Healthier, balanced meals } \\
\text { - Reducing screen time } \\
\text { - Types of physical activity and intensities }\end{array}$ & $\begin{array}{l}\text { - Family meal } \\
\text { - Review of family meal } \\
\text { - Portion sizes } \\
\text { - Regular meals } \\
\text { - Healthier, balanced meals } \\
\text { - Family meal and family time } \\
\text { - Parental role in making environment conducive for lifestyle changes }\end{array}$ \\
\hline 3 & $\begin{array}{l}\text { - Families get active } \\
\text { - Review on family physical activity } \\
\text { - Overcoming barriers in drinking water and } \\
\text { eating vegetables though creative methods } \\
\text { - Setting home activities }\end{array}$ & $\begin{array}{l}\text { - Families get active } \\
\text { - Review on family physical activity } \\
\text { - Black-and-white thinking in overcoming barriers } \\
\text { - Role of praise }\end{array}$ \\
\hline 4 & $\begin{array}{l}\text { - Stress buster } \\
\text { - Handling stress and emotional eating } \\
\text { - Sharing on the home-based circuit } \\
\text { - Mid- and long-term goal setting }\end{array}$ & $\begin{array}{l}\text { - Stress buster } \\
\text { - Handling stress and emotional eating } \\
\text { - Helping teenagers cope with bullying and poor self-esteem } \\
\text { - Showcasing successful cases of weight loss } \\
\text { - Mid- and long-term goal setting }\end{array}$ \\
\hline 5 & - Festive eating & $\begin{array}{l}\text { - Festive eating } \\
\text { - Limiting intake of high-calorie food } \\
\text { - Choosing healthier festive food }\end{array}$ \\
\hline 7 & - Summary of key topics in past sessions & - Summary of key topics in past sessions \\
\hline
\end{tabular}

SMART: specific, measurable, achievable, realistic and timely 


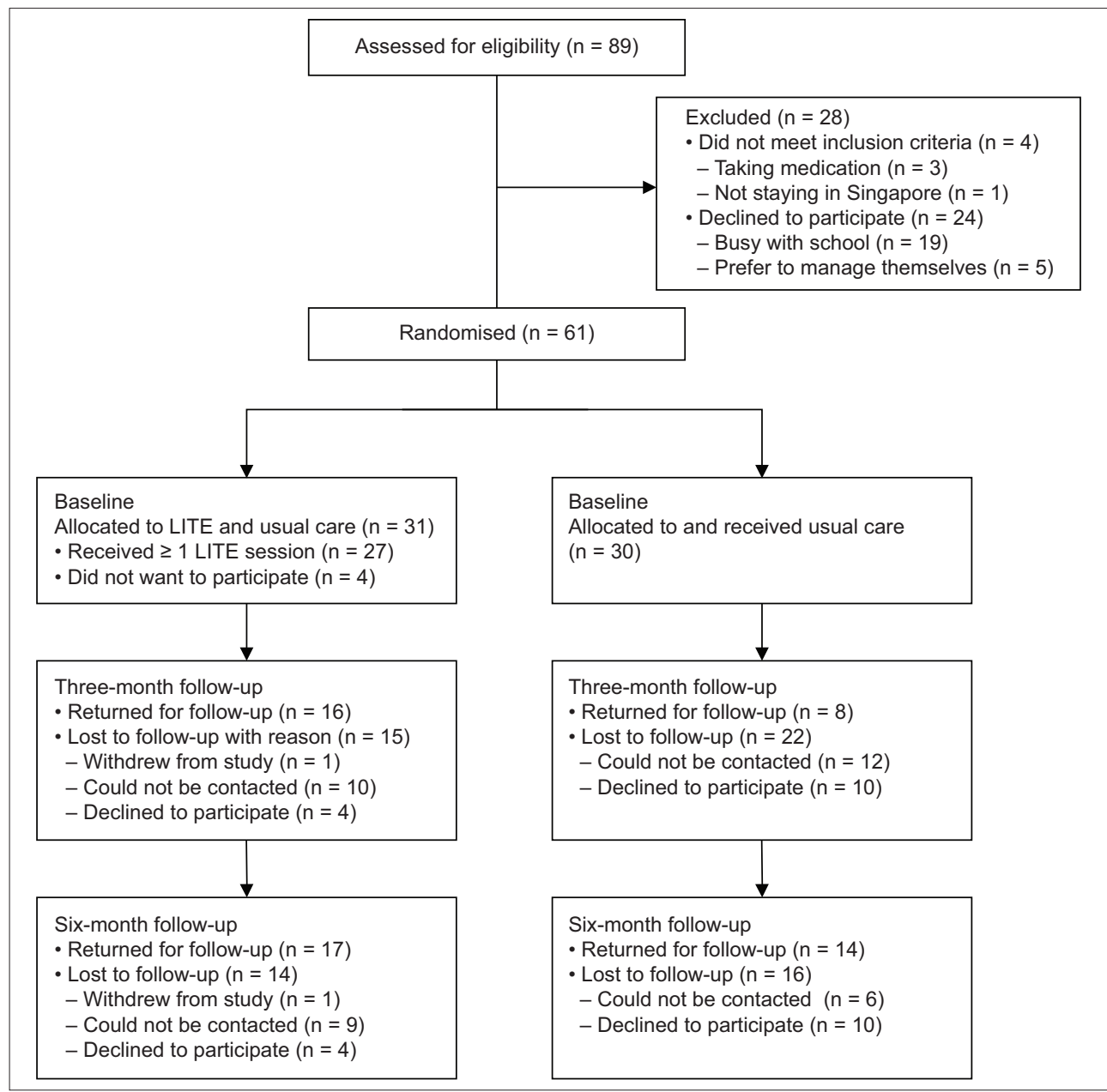

Fig. 1 Flowchart shows patient participation in the LITE (Lifestyle Intervention for TEenagers) randomised controlled trial from baseline to six months.

contents of all the sessions were delivered by Chew CSE, Lim CMM, Lim SC, Tan S and Kelly S, using standardised materials to ensure consistency in delivery. After each LITE session, the adolescent and parent completed programme evaluation questionnaires to rate each aspect of the group session and made suggestions for improving the programme.

Two trained staff members who were not involved in the allocation or intervention measured the adolescents' anthropometry and blood pressure (BP) using standard procedures and calibrated instruments. Weight was measured using the same or similar calibrated scales (Tanita HD-316; Tanita Corp, Tokyo, Japan) to the nearest $0.1 \mathrm{~kg}$, with shoes and heavy clothing removed. Weight was measured at baseline and at three and six months. Height was measured to the nearest $0.1 \mathrm{~cm}$ using a fixed stadiometer (Seca Model 240; Seca, Hamburg, Germany) at KK Women's and Children's Hospital. The BMI z-scores of the children were determined using the age-specific and gender-specific median $\mathrm{BMI}$, generalised coefficient of variation (S), and the power of the Box-Cox transformation (L) with the following formula: ([BMI/ median BMI] L) - 1/LS, based on the United States Centers for Disease Control and Prevention growth chart. ${ }^{(13)}$

Systolic and diastolic BP were measured using an automated BP monitor (Dinamap 8101; Critikon Inc, Tampa, FL, USA) after 5-10 minutes while the adoloscent rested in a supine position.
All of these measurements were taken in a private room. BP was taken at screening, randomisation, three months and six months for both the intervention and control groups. Body composition was determined by bioimpedance using the ImpediMed DF50 Body Composition Analyser (Impedimed, Pinkenba, Queensland, Australia) at screening, randomisation, three months and six months for both the intervention and control groups.

A 5-mL fasting blood sample was collected by a nationally accredited external pathology laboratory, which was also blinded to the adolescent's treatment allocation. The blood sample was analysed for fasting cholesterol (total, high-density lipoprotein and low-density lipoprotein), triglycerides, insulin and glucose using standard automated techniques in that laboratory. Metabolic biomarkers are taken at randomisation and six months for both the intervention and control groups.

The Parenting Scale ${ }^{(14)}$ and Lifestyle Behaviour Checklist $(\mathrm{LBC})^{(15)}$ were administered to the parents at baseline and at six months to assess parenting and management of problem behaviours related to eating, physical activity and overweight children, respectively. The Parenting Scale consists of 30 items that are all scored on a seven-point scale, with low scores indicating good parenting and high scores indicating dysfunctional parenting. The LBC lists 25 child problem behaviours related to eating, physical activity and overweight children aged 
Table II. Baseline demographic, anthropometric and metabolic characteristics of the study participants.

\begin{tabular}{|c|c|c|c|c|}
\hline \multirow[t]{2}{*}{ Characteristic } & \multicolumn{3}{|c|}{ No. $(\%) /$ mean \pm SD } & \multirow[t]{2}{*}{ p-value* } \\
\hline & $\begin{array}{l}\text { Total } \\
(n=61)\end{array}$ & $\begin{array}{l}\text { Usual care } \\
(n=30)\end{array}$ & $\begin{array}{l}\text { LITE + usual care } \\
(n=31)\end{array}$ & \\
\hline Age (yr) & $12.8 \pm 2.2$ & $12.6 \pm 2.1$ & $13.0 \pm 2.4$ & 0.502 \\
\hline Male gender & $37(61)$ & $18(60)$ & $19(61)$ & 0.918 \\
\hline Ethnicity & & & & 0.248 \\
\hline Chinese & $35(57)$ & $16(53)$ & $19(61)$ & \\
\hline Malay & $14(23)$ & $10(33)$ & $4(13)$ & \\
\hline Indian & $9(15)$ & $3(10)$ & $6(19)$ & \\
\hline Others & $3(5)$ & $1(3)$ & $2(6)$ & \\
\hline BMI $\left(\mathbf{k g} / \mathbf{m}^{2}\right)$ & $30.02 \pm 4.30$ & $30.11 \pm 4.43$ & $29.93 \pm 4.24$ & 0.873 \\
\hline BMI z-score & $2.12 \pm 0.33$ & $2.10 \pm 0.29$ & $2.13 \pm 0.37$ & 0.735 \\
\hline Waist circumference (cm) & $97.9 \pm 10.3$ & $97.6 \pm 11.1$ & $98.2 \pm 9.7$ & 0.821 \\
\hline Waist-height ratio & $0.62 \pm 0.05$ & $0.62 \pm 0.05$ & $0.62 \pm 0.05$ & 0.992 \\
\hline Body fat (\%) & $38.3 \pm 8.4$ & $39.2 \pm 9.2$ & $37.5 \pm 7.7$ & \\
\hline Systolic BP (mmHg) & $115 \pm 13.1$ & $115.9 \pm 14.2$ & $114.7 \pm 12.2$ & 0.723 \\
\hline Diastolic BP (mmHg) & $64.9 \pm 8.6$ & $65.2 \pm 9.4$ & $64.6 \pm 7.8$ & 0.810 \\
\hline Total cholesterol (mmol/L) & $4.88 \pm 1.13$ & $4.83 \pm 1.02$ & $4.93 \pm 1.25$ & 0.749 \\
\hline LDL-C (mmol/L) & $3.11 \pm 0.92$ & $3.05 \pm 0.74$ & $3.17 \pm 1.08$ & 0.675 \\
\hline HDL-C (mmol/L) & $1.15 \pm 0.20$ & $1.13 \pm 0.20$ & $1.17 \pm 0.21$ & 0.443 \\
\hline Triglycerides (mmol/L) & $1.35 \pm 0.72$ & $1.40 \pm 0.89$ & $1.29 \pm 0.53$ & 0.621 \\
\hline Fasting glucose (mg/dL) & $4.79 \pm 0.54$ & $4.89 \pm 0.69$ & $4.69 \pm 0.34$ & 0.214 \\
\hline 120-min glucose (mg/dL) & $6.52 \pm 1.24$ & $6.23 \pm 1.11$ & $6.76 \pm 1.31$ & 0.146 \\
\hline Insulin $(\mu \mathrm{IU} / \mathrm{mL})$ & $20.6 \pm 10.2$ & $20.1 \pm 9.8$ & $21.1 \pm 10.7$ & 0.762 \\
\hline ALT (U/L) & $45.4 \pm 38.3$ & $50.3 \pm 44.3$ & $40.8 \pm 32.3$ & 0.485 \\
\hline AST (U/L) & $33.5 \pm 24.0$ & $31.7 \pm 17.1$ & $35.1 \pm 29.2$ & 0.692 \\
\hline Parental age (yr) & $45.3 \pm 5.8$ & $43.5 \pm 3.7$ & $46.9 \pm 6.9$ & 0.023 \\
\hline Parental BMI > 23 kg/m² & $41(67)$ & $22(73)$ & $19(61)$ & 0.246 \\
\hline Parental education $<$ diploma & $39(64)$ & $23(77)$ & $16(52)$ & 0.025 \\
\hline Monthly household income < SGD 4,000 & $24(39)$ & $11(37)$ & $13(42)$ & 0.672 \\
\hline Dual-parent household & $52(85)$ & $25(83)$ & $27(87)$ & 1.000 \\
\hline Reside in 1-/2-room HDB flat & $5(8)$ & $3(10)$ & $2(6)$ & 0.666 \\
\hline
\end{tabular}

Continuous variables presented as mean \pm SD and categorical variables presented as frequency (\%). ${ }^{*}$ Calculated using independent sample $t$-test. ALT: alanine aminotransferase; AST: aspartate aminotransferase; BMI: body mass index; BP: blood pressure; HDB: Housing and Development Board; HDL: high-density lipoprotein; LDL: low-density lipoprotein; SD: standard deviation

4-11 years, and yields scores on two scales: the Problem Scale and Confidence Scale.

Assessments of adolescents' perceived family support for their exercise and eating habits ${ }^{(16)}$ were used in understanding the vehicle of change, as well as to provide evidence for those adolescents and families who had been unsuccessful in their lifestyle changes. The Social Support and Eating Habits Survey (ten items) and the Social Support and Exercise Survey (13 items) were used to measure adolescents' perceived support from family for healthy eating and exercise. Each measure used a five-point Likert-type scale ( 1 = none, 2 = rarely, 3 = a few times, $4=$ often, $5=$ very often) to indicate the frequency of social support provided by family in the previous three months.

Outcome measures were quantified as minutes per day reported performing vigorous, moderate and walking activities, while metabolic equivalent (MET) minutes per day was a measure of total health-enhancing activity. For calculation of total physical activity, the data was transformed into energy expenditure estimated as METs, using published values and recommendations from the International Physical Activity Questionnaire for Adolescents (IPAQ-A) scoring protocol. ${ }^{(17)}$ To calculate daily physical activity (MET minutes per day), the number of minutes reported in each activity level was multiplied by the specific MET score for that activity. The average serving size of vegetables over three days (inclusive of two weekdays and one weekend) was assessed by a dietitian from the three-day food record.

Data was extracted for statistical analysis using SAS software version 9.4 for Windows (SAS Inc, Cary, NC, USA). Baseline demographic, anthropometric and metabolic characteristics of study participants were compared between the LITE programme and usual care groups using the independent samples $t$-test (or Wilcoxon rank-sum test, depending on normality) and chi-square (or Fisher's exact test, where appropriate) for continuous and categorical variables, respectively. Two groups were compared in 
terms of anthropometry parameters at baseline and three months, including change at three months; metabolic and parent report of weight-related problem behaviour; parenting self-efficacy; and ineffective parenting parameters at baseline and six months, including change at six months, using independent samples $t$-test.

Sample size calculation was done using PASS software version 14 (NCSS LLC, Kaysville, Utah, USA). We determined that this pilot study had $>80 \%$ power when the estimated standard deviations were 0.8 in both the control and intervention groups using a $80 \%$ confidence interval approach with a sample size of 16 on both arms (eight on each arm). A p-value $<0.2$ was considered to be statistically significant.

\section{RESULTS}

A total of 61 adolescents were enrolled in the study, of whom 37 (61\%) were male. The patients' mean age at presentation was 12.8 \pm 2.2 years. There were no significant differences in the baseline demographic, anthropometric and metabolic characteristics of study participants in the two groups. However, parents in the LITE programme were older with higher educational attainment (Table II).

At baseline, $84 \%$ of parents reported ineffective parenting practices, $85 \%$ of parents faced problems in the child's weightrelated behaviour and $79 \%$ of parents lacked confidence in managing their child's weight-related behaviour (not shown). Overweight parents scored significantly higher on the LBC Problem Scale compared to normal weight parents $(82.1 \pm 26.1$ vs. $65.1 \pm 25.3 ; p=0.028$ ). There were no significant differences between normal weight and overweight parents in the Parenting Scale or LBC Confidence Scale. Fig. 1 shows the participant selection process up to the six-month follow-up.

Out of the 61 adolescents, 24 (40\%) completed the threemonth follow-up, with 16 (52\%) out of 31 from the LITE programme and 8 (27\%) out of 30 from usual care. Participants in the LITE programme had greater changes in weight $(-0.18$ $\pm 2.40 \mathrm{~kg}$ vs. $1.48 \pm 1.97 \mathrm{~kg} ; \mathrm{p}=0.107$ ), waist circumference $(-1.0 \pm 3.1 \mathrm{~cm}$ vs. $2.4 \pm 2.7 \mathrm{~cm} ; \mathrm{p}=0.016)$, waist-height ratio $(-0.01 \pm 0.02$ vs. $0.01 \pm 0.02 ; p=0.040)$ and systolic BP $(-3.8$ \pm 13.7 vs. $5.7 \pm 13.1 ; p=0.119)$ compared to those from usual care (Table III).

$31(51 \%)$ adolescents completed the six-month follow-up, with 17 (55\%) from the LITE programme and 14 (45\%) from usual care. Participants in the LITE programme had a greater change in 120 -minute glucose levels compared to those in usual care $(-0.24$ \pm 0.95 vs. $0.77 \pm 0.42 ; p=0.124$ ), while the usual care group had a greater reduction in fasting glucose compared to the LITE group $(-1.17 \pm 1.68$ vs. $-0.11 \pm 0.33 ; p=0.124)$ at six months. There were no significant changes in anthropometric measurements at the end of six months (Table IV). At six months, adolescents in the LITE group perceived significantly less discouragement of healthy eating from their family $(p=0.006)$ compared to the usual care group (Table V). Adjusting for parental age and education level did not change the anthropometric outcomes at three and six months. Table VI compares the baseline characteristics of the dropouts versus the attenders at six months. Those who dropped out were significantly more likely to have overweight parents
Table III. Changes in anthropometry between baseline and three months according to treatment group.

\begin{tabular}{|c|c|c|c|}
\hline \multirow[t]{2}{*}{ Variable } & \multicolumn{2}{|c|}{ Mean \pm SD } & \multirow[t]{2}{*}{ p-value* } \\
\hline & $\begin{array}{l}\text { Usual care } \\
(n=8)\end{array}$ & $\begin{array}{l}\text { LITE + usual } \\
\text { care }(n=13)\end{array}$ & \\
\hline \multicolumn{4}{|l|}{ Weight (kg) } \\
\hline Baseline & $64.74 \pm 9.54$ & $72.78 \pm 20.82$ & 0.947 \\
\hline 3 mth & $66.21 \pm 9.62$ & $72.60 \pm 20.15$ & 0.408 \\
\hline Difference & $1.48 \pm 1.97$ & $-0.18 \pm 2.40$ & 0.107 \\
\hline \multicolumn{4}{|l|}{ BMI z-score } \\
\hline Baseline & $2.13 \pm 0.37$ & $2.10 \pm 0.29$ & 0.735 \\
\hline $3 \mathrm{mth}$ & $2.03 \pm 0.32$ & $1.99 \pm 0.27$ & 0.715 \\
\hline Difference & $-0.02 \pm 0.07$ & $-0.04 \pm 0.11$ & 0.624 \\
\hline \multicolumn{4}{|c|}{ Waist circumference $(\mathrm{cm})$} \\
\hline Baseline & $97.6 \pm 11.1$ & $98.2 \pm 9.7$ & 0.821 \\
\hline $3 \mathrm{mth}$ & $94.7 \pm 6.3$ & $95.5 \pm 11.1$ & 0.960 \\
\hline Difference & $2.4 \pm 2.7$ & $-1.0 \pm 3.1$ & 0.016 \\
\hline \multicolumn{4}{|c|}{ Waist-height ratio } \\
\hline Baseline & $0.62 \pm 0.05$ & $0.62 \pm 0.05$ & 0.992 \\
\hline $3 \mathrm{mth}$ & $0.62 \pm 0.05$ & $0.61 \pm 0.05$ & 0.624 \\
\hline Difference & $0.01 \pm 0.02$ & $-0.01 \pm 0.02$ & 0.040 \\
\hline \multicolumn{4}{|l|}{ Body fat (\%) } \\
\hline Baseline & $39.2 \pm 9.2$ & $37.5 \pm 7.7$ & 0.438 \\
\hline $3 \mathrm{mth}$ & $40.0 \pm 4.4$ & $39.8 \pm 5.9$ & 0.943 \\
\hline Difference & $2.9 \pm 5.3$ & $1.0 \pm 2.4$ & 0.233 \\
\hline \multicolumn{4}{|c|}{ Systolic BP (mmHg) } \\
\hline Baseline & $115.9 \pm 14.2$ & $114.7 \pm 12.2$ & 0.723 \\
\hline $3 \mathrm{mth}$ & $121.5 \pm 13.1$ & $110.8 \pm 12.6$ & 0.065 \\
\hline Difference & $5.7 \pm 13.1$ & $-3.8 \pm 13.7$ & 0.119 \\
\hline \multicolumn{4}{|c|}{ Diastolic BP (mmHg) } \\
\hline Baseline & $65.2 \pm 9.4$ & $64.6 \pm 7.9$ & 0.810 \\
\hline $3 \mathrm{mth}$ & $64.8 \pm 5.3$ & $63.0 \pm 5.9$ & 0.476 \\
\hline Difference & $0.3 \pm 3.0$ & $-1.1 \pm 10.8$ & 0.729 \\
\hline
\end{tabular}

*Calculated using independent samples $t$-test or Mann-Whitney $U$ test, where appropriate. BMI: body mass index; BP: blood pressure; SD: standard deviation

$(p=0.094)$ and parents who lacked confidence in managing their child's weight-related behaviour $(p=0.076)$.

At three months, participants in the LITE programme had significantly more improvement in the number of servings for dietary vegetable intake compared to those from usual care $(0.56$ \pm 0.73 vs. $-0.31 \pm 0.70 ; p=0.104)$, although the difference was not significant at six months $(0.44 \pm 0.68$ vs. $0.21 \pm 0.74$; $\mathrm{p}=0.60$ ). Comparing participants in the LITE programme and participants from usual care, there was no significant difference in sedentary time at three months $(-32 \pm 654$ vs. $-225 \pm 963$; $\mathrm{p}=0.538)$ and six months (106 \pm 563 vs. $192 \pm 479 ; \mathrm{p}=0.636)$, or any significant difference in MET minutes/day at three months $(-766 \pm 3,587$ vs. $-1,599 \pm 5,977 ; p=0.661)$ and six months $(-965 \pm 4,996$ vs. $387 \pm 3,362 ; p=0.402)$.

In terms of LITE group session attendance, satisfaction and qualitative feedback, the average attendance rate was $67.7 \%$ across the five cohorts of the LITE programme, with 21 (68\%) out of 31 participants attending $\geq 5$ sessions. Attendance rates 
Table IV. Changes in anthropometry and metabolic outcomes between baseline and six months according to treatment group.

\begin{tabular}{|c|c|c|c|c|c|c|c|}
\hline \multirow[t]{2}{*}{ Variable } & \multicolumn{2}{|c|}{ Mean \pm SD } & \multirow[t]{2}{*}{ p-value* } & \multirow[t]{2}{*}{ Variable } & \multicolumn{2}{|c|}{ Mean \pm SD } & \multirow[t]{2}{*}{ p-value* } \\
\hline & Usual care & $\begin{array}{l}\text { LITE + usual } \\
\text { care }\end{array}$ & & & Usual care & $\begin{array}{l}\text { LITE + usual } \\
\text { care }\end{array}$ & \\
\hline Weight (kg) & {$[n=14]$} & {$[n=17]$} & & LDL-C (mmol/L) & {$[n=7]$} & {$[n=11]$} & \\
\hline Baseline & $64.74 \pm 9.54$ & $72.78 \pm 20.82$ & 0.947 & Baseline & $3.05 \pm 0.74$ & $3.17 \pm 1.08$ & 0.675 \\
\hline $6 \mathrm{mth}$ & $78.09 \pm 19.52$ & $77.78 \pm 22.51$ & 0.967 & $6 \mathrm{mth}$ & $2.89 \pm 0.63$ & $3.15 \pm 0.87$ & 0.49 \\
\hline Difference & $2.46 \pm 2.25$ & $1.40 \pm 2.74$ & 0.253 & Difference & $-0.53 \pm 0.63$ & $-0.26 \pm 0.35$ & 0.321 \\
\hline BMI z-score & {$[n=14]$} & {$[n=17]$} & & HDL-C (mmol/L) & {$[n=7]$} & {$[n=11]$} & \\
\hline Baseline & $2.13 \pm 0.37$ & $2.10 \pm 0.29$ & 0.735 & Baseline & $1.13 \pm 0.20$ & $1.17 \pm 0.21$ & 0.443 \\
\hline $6 \mathrm{mth}$ & $2.11 \pm 0.33$ & $2.00 \pm 0.26$ & 0.339 & $6 \mathrm{mth}$ & $1.27 \pm 0.17$ & $1.13 \pm 0.25$ & 0.195 \\
\hline Difference & $-0.04 \pm 0.09$ & $-0.04 \pm 0.16$ & 0.951 & Difference & $0.07 \pm 0.23$ & $-0.05 \pm 0.21$ & 0.343 \\
\hline $\begin{array}{l}\text { Waist circumference } \\
\text { (cm) }\end{array}$ & {$[n=14]$} & {$[n=17]$} & & $\begin{array}{l}\text { Triglycerides } \\
\text { (mmol/L) }\end{array}$ & {$[n=7]$} & {$[n=11]$} & \\
\hline Baseline & $97.6 \pm 11.1$ & $98.2 \pm 9.7$ & 0.821 & Baseline & $1.40 \pm 0.88$ & $1.29 \pm 0.53$ & 0.621 \\
\hline $6 \mathrm{mth}$ & $99.1 \pm 13.0$ & $95.7 \pm 12.1$ & 0.466 & $6 \mathrm{mth}$ & $1.21 \pm 0.33$ & $1.25 \pm 0.60$ & 0.903 \\
\hline Difference & $0.1 \pm 4.6$ & $-1.5 \pm 4.7$ & 0.359 & Difference & $-0.15 \pm 0.68$ & $0.11 \pm 0.62$ & 0.466 \\
\hline Waist-height ratio & {$[n=14]$} & {$[n=17]$} & & $\begin{array}{l}\text { Fasting glucose } \\
\text { (mg/dL) }\end{array}$ & {$[n=4]$} & {$[n=10]$} & \\
\hline Baseline & $0.62 \pm 0.05$ & $0.62 \pm 0.05$ & 0.992 & Baseline & $4.89 \pm 0.69$ & $4.69 \pm 0.34$ & 0.214 \\
\hline $6 \mathrm{mth}$ & $0.62 \pm 0.06$ & $0.59 \pm 0.05$ & 0.115 & $6 \mathrm{mth}$ & $4.58 \pm 0.50$ & $4.61 \pm 0.26$ & 0.863 \\
\hline Difference & $-0.01 \pm 0.03$ & $-0.02 \pm 0.04$ & 0.468 & Difference & $-1.17 \pm 1.68$ & $-0.11 \pm 0.33$ & 0.124 \\
\hline Body fat (\%) & {$[n=14]$} & {$[n=17]$} & & $\begin{array}{l}\text { 120-min glucose } \\
\text { (mg/dL) }\end{array}$ & {$[n=4]$} & {$[n=10]$} & \\
\hline Baseline & $39.2 \pm 9.2$ & $37.5 \pm 7.7$ & 0.438 & Baseline & $6.23 \pm 1.11$ & $6.76 \pm 1.31$ & 0.146 \\
\hline $6 \mathrm{mth}$ & $43.1 \pm 8.1$ & $40.3 \pm 7.8$ & 0.336 & $6 \mathrm{mth}$ & $6.45 \pm 1.58$ & $6.57 \pm 1.89$ & 0.913 \\
\hline Difference & $2.3 \pm 6.1$ & $3.8 \pm 6.0$ & 0.512 & Difference & $0.77 \pm 0.42$ & $-0.24 \pm 0.95$ & 0.124 \\
\hline Systolic BP (mmHg) & {$[n=14]$} & {$[n=17]$} & & Insulin ( $\mu \mid \mathrm{I} / \mathrm{mL})$ & {$[n=4]$} & {$[n=10]$} & \\
\hline Baseline & $115.9 \pm 14.2$ & $114.7 \pm 12.2$ & 0.723 & Baseline & $20.1 \pm 9.8$ & $21.1 \pm 10.7$ & 0.762 \\
\hline $6 \mathrm{mth}$ & $115.9 \pm 10.9$ & $114.8 \pm 7.1$ & 0.725 & $6 \mathrm{mth}$ & $15.9 \pm 4.2$ & $19.8 \pm 11.5$ & 0.525 \\
\hline Difference & $-3.1 \pm 11.8$ & $1.1 \pm 12.3$ & 0.348 & Difference & $2.9 \pm 2.9$ & $0.1 \pm 4.8$ & 0.478 \\
\hline Diastolic BP (mmHg) & {$[n=14]$} & {$[n=17]$} & & ALT (U/L) & {$[n=6]$} & {$[n=10]$} & \\
\hline Baseline & $65.2 \pm 9.4$ & $64.6 \pm 7.9$ & 0.810 & Baseline & $50.3 \pm 44.3$ & $40.8 \pm 32.3$ & 0.485 \\
\hline $6 \mathrm{mth}$ & $66.3 \pm 7.1$ & $63.3 \pm 6.5$ & 0.237 & $6 \mathrm{mth}$ & $67.0 \pm 82.0$ & $25.4 \pm 11.2$ & 0.128 \\
\hline Difference & $-0.8 \pm 10.0$ & $-0.4 \pm 9.4$ & 0.923 & Difference & $4.0 \pm 61.1$ & $-5.5 \pm 12.8$ & 0.714 \\
\hline $\begin{array}{l}\text { Total cholesterol } \\
\text { (mmol/L) }\end{array}$ & {$[n=7]$} & {$[n=11]$} & & AST (U/L) & {$[n=6]$} & {$[n=10]$} & \\
\hline Baseline & $4.83 \pm 1.02$ & $4.93 \pm 1.25$ & 0.749 & Baseline & $31.7 \pm 17.1$ & $35.1 \pm 29.2$ & 0.692 \\
\hline $6 \mathrm{mth}$ & $4.71 \pm 0.67$ & $4.86 \pm 0.87$ & 0.705 & $6 \mathrm{mth}$ & $39.7 \pm 30.9$ & $24.7 \pm 6.7$ & 0.154 \\
\hline Difference & $-0.53 \pm 0.84$ & $-0.26 \pm 0.6$ & 0.496 & Difference & $9.0 \pm 22.5$ & $-1.7 \pm 6.7$ & 0.294 \\
\hline
\end{tabular}

Value of $\mathrm{n}$ is listed in cases where some data was unavailable, and percentages were calculated based on available data. ${ }^{*} \mathrm{Calculated}$ using independent sample $t$-test or Mann-Whitney $U$ test, where appropriate. ALT: alanine aminotransferase; AST: aspartate aminotransferase; BMI: body mass index; BP: blood pressure; HDL: highdensity lipoprotein; LDL: low-density lipoprotein; SD: standard deviation

at the weekly LITE group sessions (Sessions 1-4) were $79.8 \%$ and attendance rates at the monthly booster sessions (Sessions $5-7)$ were $51.6 \%$. The programme was well received by the adolescent study participants, with $84 \%$ indicating that it was useful. Similarly, $96 \%$ of the parents said that they enjoyed the programme and $91 \%$ would recommend the programme to others. $84 \%$ of the parents rated the quality of the programme as good or excellent. A significantly higher proportion of those who attended $<5$ sessions had a monthly income $<$ SGD 4,000 $(p<0.001)$ and the parents had an educational attainment of less than diploma $(p=0.029)$. No difference was found in other baseline demographic variables. Adjusting for attendance did not change anthropometric outcomes at three and six months.

Qualitative feedback from participants indicated that future programmes should incorporate a higher number of sessions, possibly up to 12 sessions, as parents indicated that four weekly sessions were insufficient to effect more lasting changes in eating and physical activity behaviours. They also suggested forming a parent support group to help in healthy lifestyle maintenance. 
Table V. Changes in parent reports of weight-related problem behaviour, parenting self-efficacy, ineffective parenting and adolescent reports of family support for eating and exercise.

\begin{tabular}{|c|c|c|c|}
\hline \multirow[t]{2}{*}{ Variable } & \multicolumn{2}{|c|}{ Mean \pm SD } & \multirow[t]{2}{*}{ p-value* } \\
\hline & $\begin{array}{l}\text { Usual care } \\
(n=12)\end{array}$ & $\begin{array}{l}\text { LITE + usual } \\
\text { care }(n=16)\end{array}$ & \\
\hline \multicolumn{4}{|c|}{ LBC Problem Scale } \\
\hline Baseline & $70.7 \pm 26.7$ & $80.6 \pm 26.7$ & 0.186 \\
\hline $6 \mathrm{mth}$ & $66.2 \pm 23.3$ & $73.9 \pm 33.9$ & 0.500 \\
\hline Difference & $-9.5 \pm 18.9$ & $4.5 \pm 39$ & 0.288 \\
\hline \multicolumn{4}{|c|}{ LBC Confidence Scale } \\
\hline Baseline & $128.6 \pm 67.3$ & $142.5 \pm 49.6$ & 0.440 \\
\hline $6 \mathrm{mth}$ & $143.6 \pm 57.4$ & $156.8 \pm 50.4$ & 0.514 \\
\hline Difference & $0.4 \pm 99.4$ & $33.7 \pm 54.9$ & 0.378 \\
\hline \multicolumn{4}{|c|}{ Parenting Scale total } \\
\hline Baseline & $3.5 \pm 0.6$ & $3.62 \pm 0.5$ & 0.437 \\
\hline $6 \mathrm{mth}$ & $3.47 \pm 0.8$ & $3.71 \pm 0.8$ & 0.455 \\
\hline Difference & $-0.06 \pm 1$ & $0.12 \pm 0.8$ & 0.607 \\
\hline \multicolumn{4}{|c|}{ Encourage healthy eating habits } \\
\hline Baseline & $14.5 \pm 3.9$ & $16.66 \pm 4.2$ & 0.048 \\
\hline $6 \mathrm{mth}$ & $15.6 \pm 4.6$ & $17.22 \pm 4.2$ & 0.299 \\
\hline Difference & $1.4 \pm 4.7$ & $0.06 \pm 5.1$ & 0.455 \\
\hline \multicolumn{4}{|c|}{ Discourage healthy eating habits } \\
\hline Baseline & $10.9 \pm 3.5$ & $12.1 \pm 4.7$ & 0.270 \\
\hline $6 \mathrm{mth}$ & $12.93 \pm 4.1$ & $9.22 \pm 2.9$ & 0.006 \\
\hline Difference & $1.29 \pm 3.5$ & $-3.06 \pm 4.4$ & 0.006 \\
\hline \multicolumn{4}{|c|}{ Participate in exercise } \\
\hline Baseline & $24.6 \pm 9.8$ & $25.4 \pm 11$ & 0.756 \\
\hline $6 \mathrm{mth}$ & $22.4 \pm 7.6$ & $27.6 \pm 7.7$ & 0.068 \\
\hline Difference & $0.07 \pm 0.3$ & $0.03 \pm 0.2$ & 0.542 \\
\hline \multicolumn{4}{|c|}{ Rewards and punishment for exercise } \\
\hline Baseline & $5.2 \pm 2.1$ & $5.2 \pm 2.6$ & 0.946 \\
\hline $6 \mathrm{mth}$ & $5.6 \pm 2.9$ & $4.9 \pm 2.2$ & 0.438 \\
\hline Difference & $0.4 \pm 3.1$ & $-0.3 \pm 2.5$ & 0.518 \\
\hline
\end{tabular}

${ }^{*}$ Calculated using independent sample $t$-test or Mann-Whitney $U$ test, where appropriate. LBC: Lifestyle Behaviour Checklist; LITE: Lifestyle Intervention for TEenagers; SD: standard deviation

\section{DISCUSSION}

Participants in the LITE programme showed significant decreases in weight, waist circumference, waist-height ratio and systolic $\mathrm{BP}$, and increased dietary intake of vegetables at the end of three months in the LITE programme compared to usual care. The dropout rate of the programme was lower than in usual care. At six months, there was a significant improvement in adolescents' perception of family support for eating habits in the LITE group but no significant difference in anthropometric measurements.

The lack of significant differences in waist circumference, waist-height ratio and systolic BP between the two groups at six months is consistent with the previously reported difficulty of maintaining a healthy lifestyle. ${ }^{(18)}$ Another possibility was that the monthly booster sessions were more poorly attended $(51.6 \%)$ than the weekly sessions $(79.8 \%)$, as the booster sessions were held on Friday evenings as opposed to the weekly sessions on Saturday mornings. Parents and adolescents cited school and work commitments as common barriers for not attending the booster sessions. Reductions in waist circumference and waist-height ratio are of clinical importance, as waist circumference and waist-height ratio were shown to have a stronger correlation with cardiometabolic outcomes compared to $\mathrm{BMI}$ in a systematic review. ${ }^{(19)}$ This correlation is also seen in the significant reduction in systolic blood pressure with the LITE programme and usual care.

A significantly higher proportion of dropping out occurred among overweight parents and parents who lacked confidence in managing their child's weight-related behaviour. This is consistent with previous findings that parental overweight and lack of confidence are strongly associated with childhood obesity $^{(20)}$ and likely contribute to dropping out from childhood obesity programmes. In our study, overweight parents also faced more problems related to management of their child's weightrelated behaviour. Collectively, a large proportion of parents experienced difficulty in managing their child's weight-related problems, and ineffective parenting practices, particularly in overweight parents, and the lack of significant improvement with intervention suggests the need for more tailored sessions on positive parenting.

For the LITE programme, there was a higher proportion of non-attendance among parents who had lower income and educational attainment. Future studies are needed to examine the barriers faced by parents of lower socioeconomic status and to adapt the intervention for better engagement with this group.

Our finding that there was a significant improvement in adolescents' perception that their family discouraged healthy eating is a positive sign of the LITE programme's success in improving family support for eating habits. The absence of a significant improvement in adolescents' perception of exercise habits could be due to the lack of parental active participation during the adolescent-only physical activity education sessions. Future programmes could explore having the active participation of parents during the physical activity education sessions. The lack of improvement in recorded physical activity based on the IPAQ-A was likely due to the adolescents' recall bias at baseline when they completed the questionnaire; this requires modification in a subsequent larger trial to reduce bias.

Strengths of the current study include its use of randomisation in evaluating the LITE programme together with questionnaires as a qualitative tool to evaluate the study. We demonstrated that the LITE programme is feasible and acceptable based on the high participation rates, the positive comments in the LITE programme evaluation questionnaire and the high level of satisfaction by both adolescents and their parents, which is encouraging for its continued use. Limitations of the study include its small sample size that was not powered to detect statistical significance in the changes as well as a high dropout rate.

The LITE programme demonstrates the acceptability and feasibility of a group family-based intervention in a multiracial population where there is a paucity of intervention trials. The group setting suggests that it has potential to be scalable in a community setting, led by a non-specialist who is trained by a 
Table VI. Baseline characteristics of dropouts versus attenders at six months.

\begin{tabular}{|c|c|c|c|}
\hline \multirow[t]{2}{*}{ Characteristic } & \multicolumn{2}{|c|}{ Mean \pm SD/no. (\%) } & \multirow[t]{2}{*}{ p-value* } \\
\hline & $\begin{array}{l}\text { Dropouts } \\
(\mathbf{n = 3 0 )}\end{array}$ & $\begin{array}{l}\text { Attenders } \\
(\mathbf{n}=\mathbf{3 1})\end{array}$ & \\
\hline Age (yr) & $12.1 \pm 2.0$ & $12.5 \pm 2.4$ & 0.462 \\
\hline Male gender & $18(60)$ & $19(61)$ & 0.563 \\
\hline Ethnicity & & & 0.188 \\
\hline Chinese & $14(47)$ & $21(68)$ & \\
\hline Malay & $8(27)$ & $6(19)$ & \\
\hline Indian & $7(23)$ & $2(6)$ & \\
\hline Others & $1(3)$ & $2(6)$ & \\
\hline BMI $\left(\mathbf{k g} / \mathbf{m}^{2}\right)$ & $30.41 \pm 4.51$ & $29.65 \pm 4.12$ & 0.495 \\
\hline BMI z-score & $2.14 \pm 0.39$ & $2.09 \pm 0.26$ & 0.551 \\
\hline Waist circumference (cm) & $97.8 \pm 9.1$ & $98.0 \pm 11.6$ & 0.963 \\
\hline Waist-height ratio & $0.63 \pm 0.05$ & $0.62 \pm 0.05$ & 0.347 \\
\hline Body fat (\%) & $38.2 \pm 8.1$ & $38.4 \pm 8.9$ & 0.938 \\
\hline Parental age (yr) & $43.5 \pm 6.7$ & $45.2 \pm 4.8$ & 0.947 \\
\hline Parental BMI > $23 \mathrm{~kg} / \mathrm{m}^{2}$ & $22(73)$ & $19(61)$ & 0.094 \\
\hline Parental education < diploma & $21(70)$ & $21(68)$ & 0.534 \\
\hline Monthly household income < SGD 4,000 & $14(47)$ & $10(32)$ & 0.187 \\
\hline Dual-parent household & $26(87)$ & $26(84)$ & 0.522 \\
\hline Reside in 1-/2-room HDB flat & $2(7)$ & $3(10)$ & 0.516 \\
\hline LBC Problem Scale & $75.1 \pm 30.0$ & $77.4 \pm 24.2$ & 0.758 \\
\hline LBC Confidence Scale & $118.3 \pm 56.9$ & $149.8 \pm 58.8$ & 0.076 \\
\hline Parenting Scale total & $3.5 \pm 0.6$ & $3.6 \pm 0.6$ & 0.688 \\
\hline Encourage healthy eating habits & $15.6 \pm 4.3$ & $15.5 \pm 4.2$ & 0.962 \\
\hline Discourage healthy eating habits & $11.0 \pm 4.1$ & $12.0 \pm 4.2$ & 0.376 \\
\hline Participate in exercise & $25.8 \pm 10.6$ & $24.2 \pm 10.2$ & 0.576 \\
\hline Rewards and punishment for exercise & $5.1 \pm 2.1$ & $5.3 \pm 2.6$ & 0.707 \\
\hline
\end{tabular}

Continuous variables presented as mean \pm SD and categorical variables presented as frequency $(\%)$. *Independent sample $t$-test or chi-square test, where appropriate. BMI: body mass index; HDB: Housing and Development Board; LBC: Lifestyle Behaviour Checklist; SD: standard deviation

multidisciplinary weight management team using standardised resources. Suggestions from adolescents and parents have provided valuable input for further development of the LITE programme to enable a modified programme to be evaluated in a larger-scale randomised trial.

\section{ACKNOWLEDGEMENTS}

We would like to thank all the children and adolescents who participated in the study as well as their families. We also thank all the paediatricians, nurses and dieticians running the weight management clinic and Dr Lee Jan Hau and Dr Chong Shu-Ling, KK Women's and Children's Hospital, Singapore, for reviewing the manuscript. This study was funded by Ronald McDonald House Charities Singapore.

\section{REFERENCES}

1. NCD Risk Factor Collaboration (NCD-RisC). Worldwide trends in body-mass index, underweight, overweight, and obesity from 1975 to 2016: a pooled analysis of 2416 population-based measurement studies in 128.9 million children, adolescents, and adults. Lancet 2017; 390:2627-42.

2. Riley M, Bluhm B. High blood pressure in children and adolescents. Am Fam Physician 2012; 85:693-700.

3. Whitaker RC, Wright JA, Pepe MS, Seidel KD, Dietz WH. Predicting obesity in young adulthood from childhood and parental obesity. N Engl J Med 1997; 337:869-73.

4. Finkelstein EA, Trogdon JG, Cohen JW, Dietz W. Annual medical spending attributable to obesity: payer-and service-specific estimates. Health Aff (Millwood) 2009; 28:w822-31.

5. Nguyen B, Shrewsbury VA, O'Connor J, et al. Twelve-month outcomes of the loozit randomized controlled trial: a community-based healthy lifestyle program for overweight and obese adolescents. Arch Pediatr Adolesc Med 2012; 166:170-7.

6. Hong WJN, Huang HL, Rajasegaran K, et al. Presence of obesity related comorbidities associated with lower attrition rate in pediatric weight management program. J Child Obes 2017; 2:10.

7. Reinehr T, Andler W. Changes in the atherogenic risk factor profile according to degree of weight loss. Arch Dis Child 2004; 89:419-22.

8. Reinehr T, Kleber M, Toschke AM. Lifestyle intervention in obese children is associated with a decrease of the metabolic syndrome prevalence. Atherosclerosis 2009; 207:174-80.

9. Reinehr T. Lifestyle intervention in childhood obesity: changes and challenges. Nat Rev Endocrinol 2013; 9:607-14.

10. Caprio S, Daniels SR, Drewnowski A, et al. Influence of race, ethnicity, and culture on childhood obesity: implications for prevention and treatment: a consensus statement of Shaping America's Health and the Obesity Society. Diabetes Care 2008; 31:2211-21.

11. Board HP. Birth to eighteen years. Dietary tips for your child's wellbeing. May 2012. https://www.healthhub.sg/sites/assets/Assets/PDFs/HPB/Children/birth18EnglishFINALA4.pdf. Accessed September 7, 2019.

12. Health Hub, Health Promotion Board, Singapore. National Physical Activity Guidelines: Summary Guide for Professionals. Available at: https://www. healthhub.sg/sites/assets/Assets/PDFs/HPB/PhysicalActivityPDFs/NPAG_ Summary_Guide.pdf. Accessed September 7, 2019. 
13. Kuczmarski RJ, Ogden CL, Grummer-Strawn LM, et al. CDC growth charts: United States. Adv Data 2000; (314):1-27.

14. Arnold DS, O'Leary SG, LS Wolff, M. Acker MM. The Parenting Scale: a measure of dysfunctional parenting in discipline situations. Psychol Assess 1993; 5:137-44

15. West F, Sanders MR. The Lifestyle Behaviour Checklist: a measure of weightrelated problem behaviour in obese children. Int J Pediatr Obes 2009; 4:266-73.

16. Johnson ER, Carson TL, Affuso O, Hardy CM, Baskin ML. Relationship between social support and body mass index among overweight and obese African American women in the rural deep South, 2011-2013. Prev Chronic Dis 2014; 11:E224.
17. Mannocci A, Masala D, Mei D, et al. International Physical Activity Questionnaire for Adolescents (IPAQ A): reliability of an Italian version. Minerva Pediatr 2018 Jan 29. https://doi.org/10.23736/S0026-4946.16.04727-7. [Epub ahead of print]

18. McLean N, Griffin S, Toney K, Hardeman W. Family involvement in weight control, weight maintenance and weight-loss interventions: a systematic review of randomised trials. Int J Obes Relat Metab Disord 2003; 27:987-1005.

19. Browning LM, Hsieh SD, Ashwell M. A systematic review of waist-to-height ratio as a screening tool for the prediction of cardiovascular disease and diabetes: 0.5 could be a suitable global boundary value. Nutr Res Rev 2010; 23:247-69.

20. Golan M. Parents as agents of change in childhood obesity--from research to practice. Int J Pediatr Obes 2006; 1:66-76.

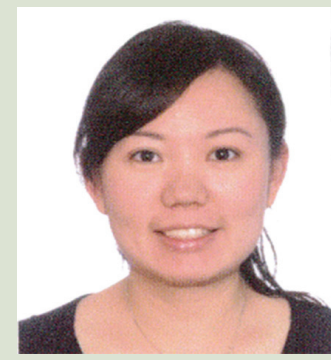

About the First Author

Dr Elaine Chew has been working as a specialist in paediatric medicine and adolescent health since 2011. She is currently a Senior Consultant in Adolescent Medicine at KK Women's and Children's Hospital, Singapore, and Adjunct Assistant Professor at Duke-NUS Medical School. Her research interest is in family-based interventions for paediatric obesity. She has obtained several research grants to conduct health services research on family-based interventions and the use of mobile applications in children and adolescents with obesity, and has published her research findings in journals. Her other research interest is in adolescents with eating disorders. She is interested in the upstream prevention of both eating disorders and obesity. 